Жуковська О.А.

канд. фіз.-мат. наук, доцент

ORCID ID: 0000-0003-1110-9696

\author{
Нікітіна П.А. \\ Національний технічний університет Украӥни \\ «Київський політехнічний інститут імені Ігоря Сікорського»
}

\title{
ЕКОНОМІКО-МАТЕМАТИЧНЕ МОДЕЛЮВАННЯ РИНКОВОЇ ДІЯЛЬНОСТІ КОМПАНІї
}

\author{
ЭКОНОМИКО-МАТЕМАТИЧЕСКОЕ МОДЕЛИРОВАНИЕ \\ РЫНОЧНОЙ ДЕЯТЕЛЬНОСТИ КОМПАНИИ
}

\section{ECONOMIC AND MATHEMATICAL MODELLING OF COMPANY BUSINESS ON THE MARKET}

У статті побудована математична модель аналізу і прогнозування діяльності компанії з урахуванням займаної частки ринку та зовнішніх інвестицій. Побудовано математичну залежність динаміки приросту активів від зміни з часом частки ринку компанії та загальної ємності ринку. Показано, що запропонована модель дозволяє дослідити динаміку розвитку та проаналізувати різні стратегії поведінки компанії на ринку. Розглянуто такі можсливі стратегії, основною метою яких є збільшення частки ринку: дотримання старої товарної політики - збереження або зменшення ціни на товар без залучання інвестицій, або кардинальної зміни товарної політики шляхом виведення нового інноваційного продукту на ринок за рахунок введення інвестичій. Для розглядуваних стратегій проведено порівняння динаміки основних показників: частки ринку, прибутку та активів компанії. В результаті визначена ефективна стратегія, яка дозволить зберегти та посилити конкурентну позицію компанії на ринку, трунтуючись не тільки на показниках доходу компанії та розміру ї активів, а і частки ринку. Отже, запропонована модель дозволяє визначити напрям товарної політики компанії, оперуючи основними показниками ї̈ діяльності, як фінансовими, так $і$ маркетинговими: ринковою часткою, прибутком та розміром активів компанії. ва стратегія.

Ключові слова: ринкова частка, конкурентоспроможність, ефективність, маркетинго-

В статье построена математическая модель анализа и прогнозирования деятельности компании с учетом занимаемой доли рынка и внешних инвестиций. Построено математическую зависимость динамики прироста активов от изменения со временем доли рынка компании и общей емкости рынка. Показано, что предложенная модель позволяет исследовать динамику развития и проанализировать различные стратегии поведения компании на рынке. Рассмотрены такие возможные стратегии, основной иелью которых является увеличение доли рынка: соблюдение старой товарной политики - сохранение или уменьшение иенны на товар без вовлечения инвестищий, или кардинальное изменение товарной политики путем вывода нового инновационного продукта на рынок за счет введения инвестиций. Для рассматриваемых стратегий проведено сравнение динамики основных показателей: доли рынка, прибыли и активов компании. В результате определена эффективная стратегия, которая позволит сохранить и усилить конкурентную позицию компании на рынке, основываясь не только на показателях дохода компании и размера ее активов, а и доли рынка. Таким образом, предлагаемая модель позволяет определить направление товарной политики компании, оперируя основными показателями ее деятельности, как финансовыми, так $u$ маркетинговыми: рыночной долей, прибылью и размером активов компании. 
Ключевые слова: доля рынка, конкурентоспособность, эффективность, маркетинговая стратегия.

The mathematical model for analysis and forecasting a company business in view of the market share and external investment is described in the research paper. The mathematical relationship of the dynamics of company assets growth from the time variation of the market share and the overall market size is built. The proposed model allows us to investigate and analyse the dynamics of the various company strategy depending on the company's behaviour in the market. Possible strategies, the main purpose of which is to increase market share, were considered: continuing the old product policy - maintaining or reducing the price of the goods without investments involvement, or a fundamental change in product policy by launching a new innovative product in the market through investments. Dynamics of the main indicators is compared for these strategies: market share, company profit and company assets. As a result, the effective strategy was determined to keep and enhance the company's competitive position in the market, based not only on the performance of the company income and the size of its assets, but also on market share. Thus, the proposed model allows us to determine the direction of product policy of the company, using the main indicators of its activity, both financial and marketing: market share, profit and size of the company assets.

Keywords: market share, competitiveness, efficiency, marketing strategy.

Вступ. У сучасних ринкових умовах основним завданням вітчизняних підприємств є збереження та посилення своїх конкурентних позицій, так як подальшим розвитком ринку кожна компанія відчуває все більший тиск від споріднених компаній. Тому на даний час актуальною є задача не тільки збереження, а й збільшення частки ринку продукції компанії. Для вибору ефективної стратегії поведінки компанії на ринку з метою збільшення частки ринку необхідно не тільки провести дослідження ємності ринку з метою виявлення нових сегментів, визначення тенденцій розвитку ринку, а й врахувати можливості компанії задовільнити потреби у даному товарі. На даний час окремо існують математичні моделі аналізу та розвитку підприємства [1-7] та методи дослідження ємності ринку [8-13]. Тому потрібен механізм для ефективної оцінки і побудови стратегії власної діяльності, який дозволив би визначити положення компанії на ринку відносно ії конкурентів та динаміку розвитку компанії.

Постановка завдання. Метою даної статті $є$ побудова моделі аналізу розвитку підприємства, яка дозволяє обрати ефективну стратегію поведінки на ринку.

Методологія: методи визначення частки ринку, ємності ринку, динамічна модель розвитку підприємства.

Результати дослідження. Для побудови конструктивної моделі ринкової

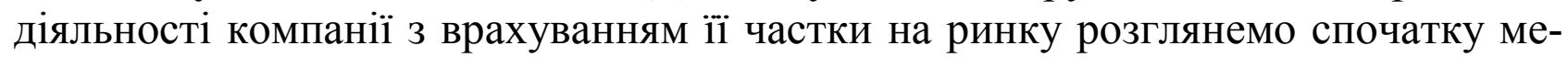
тод оцінки частки ринку $S(t)$ компанї на основі функції корисності $f_{i}(t)$, яку споживачі ставлять у відповідність до продукту $i$-ої фірми [8]:

$$
S_{i}(t)=\frac{\exp f_{i}(t)}{1+\sum_{j=1}^{N} \exp f_{j}(t)}, \quad i=1, \ldots, N-1
$$


Очевидно, що величина випуску продукції $V(t)$ у вартісному вимірі не повинна перевищувати можливості ринку поглинути товар:

$$
V(t) \leq S(t) N,
$$

де $N$ - ємність ринку на момент часу $t$.

Загальний прибуток $R^{*}(t)$, який отримує компанія від функціонування на ринку до оподаткування, характеризується рівнянням

$$
R^{*}(t)=(1-c) V(t),
$$

де $c$ - гранична собівартість продукції, а

Наступне рівняння описує величину чистого прибутку $R(t)$ після податкових відрахувань $L(t)$ :

$$
R(t)=R^{*}(t)-L(t) .
$$

Величина податкових зборів на прибуток визначається так

$$
L(t)=\tau R(t),
$$

де $\tau$ - ставка оподаткування прибутку, яка на даний момент в Україні складає $18 \%$.

Підприємство сплачує дивіденди $D(t)$ своїм акціонерам, розмір яких визначається в залежності від чистого прибутку підприємства

$$
D(t)=\phi R(t),
$$

де $\phi$ - коефіцієнт пропорційності, $0 \leq \phi \leq 1$.

Динаміка приросту активів компанії $A(t)$ за рахунок власних коштів та зовнішніх інвестицій описується рівнянням

$$
\frac{d A}{d t}=\xi(R(t)-D(t))+I(t)-\lambda A(t),
$$

де $I(t)$ - зовнішні інвестиції, $\xi$ - частка прибутку, що відраховується на реінвестування, $0 \leq \xi \leq 1 ; \lambda$ - коефіцієнт вибуття активів, $0 \leq \lambda \leq 1$.

Система співвідношень (1) - (7) зводиться до лінійного неоднорідного диференціального рівняння

$$
\frac{d A}{d t}=\xi \frac{1-\phi}{1+\tau}(1-c) S(t) N+I(t)-\lambda A(t)
$$


Загальним розв’язком диференціального рівняння є:

$$
\left.A(t)=e^{-\lambda t}\left[\int e^{\lambda t}(\alpha S(t)+I(t)) d t\right)+C\right],
$$

де $\alpha=\frac{\xi(1-\phi)(1-c) N}{1+\tau}$.

Значення $C$ визначаємо 3 рівняння (9) при початкових умовах $t=t_{0}$ $A(t)=A\left(t_{0}\right)$.

Побудована модель перевірена на реальних даних за попередні 12 місяців на 3 основних показниках - частка ринку, чистий прибуток, активи компанії.

Результати відображені на рисунку 1.
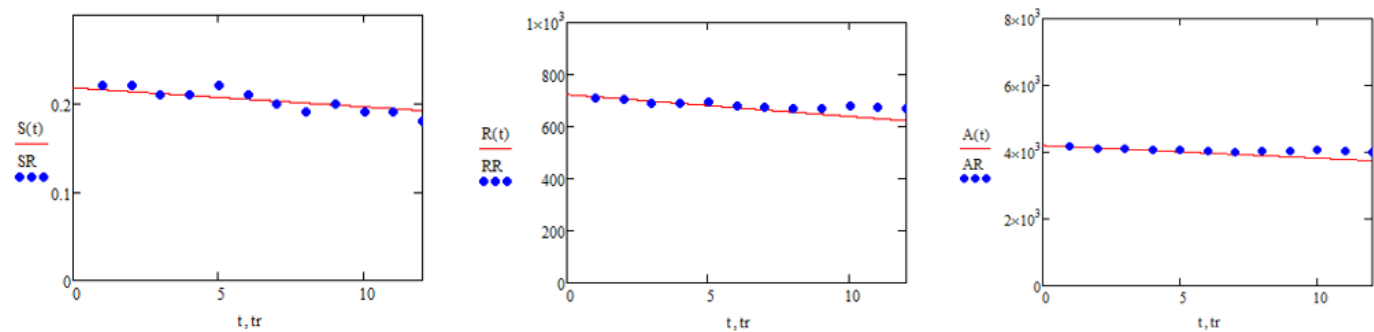

Рис. 1. Порівняння зліва-направо ринкової частки, прибутку та активів компанії (виражених у гр. од.) фактичних та розрахованих за моделлю (9)

Середня відносна похибка для показників:

- частка ринку $7.2 \%$

- чистий прибуток $8.3 \%$

- активи компанії 6.5\%

3 метою визначення ефективної стратегії на ринку на основі побудованої моделі та даних за 36 місяців проаналізована динаміка зміни показників на наступні 12 місяців при трьох стратегіях поведінки:

1) збереження старої ціни, інвестиції дорівнюють нулю (рис. 2),

2) зменшення ціни товару, інвестиції дорівнюють нулю (рис. 3),

3) виведення нового інноваційного продукту на ринок, що потребує введення додаткових інвестицій (рис. 4).
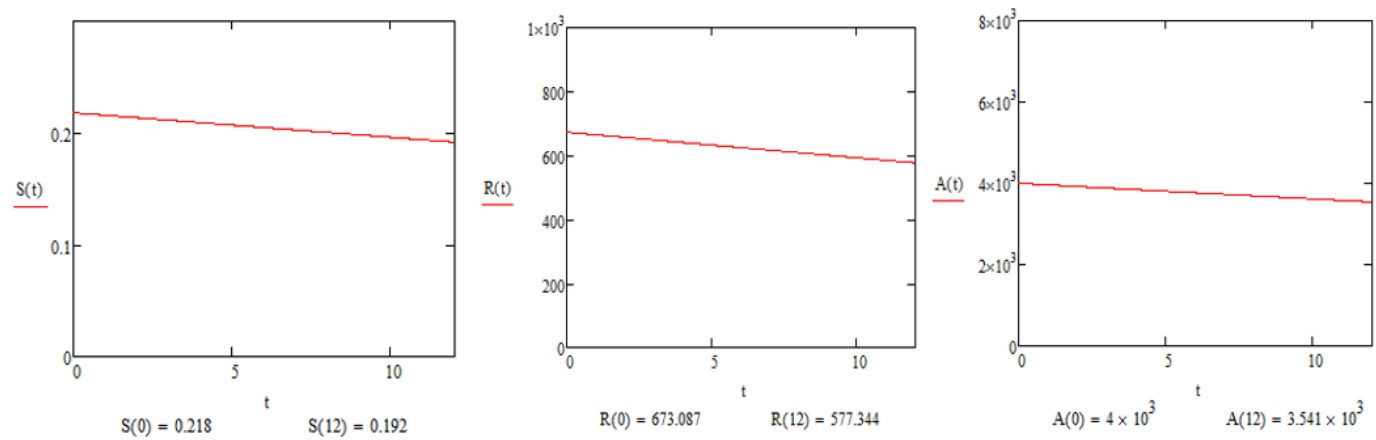

Рис. 2. Динаміка зліва-направо ринкової частки, прибутку та активів компанії (виражених у гр. од.) 

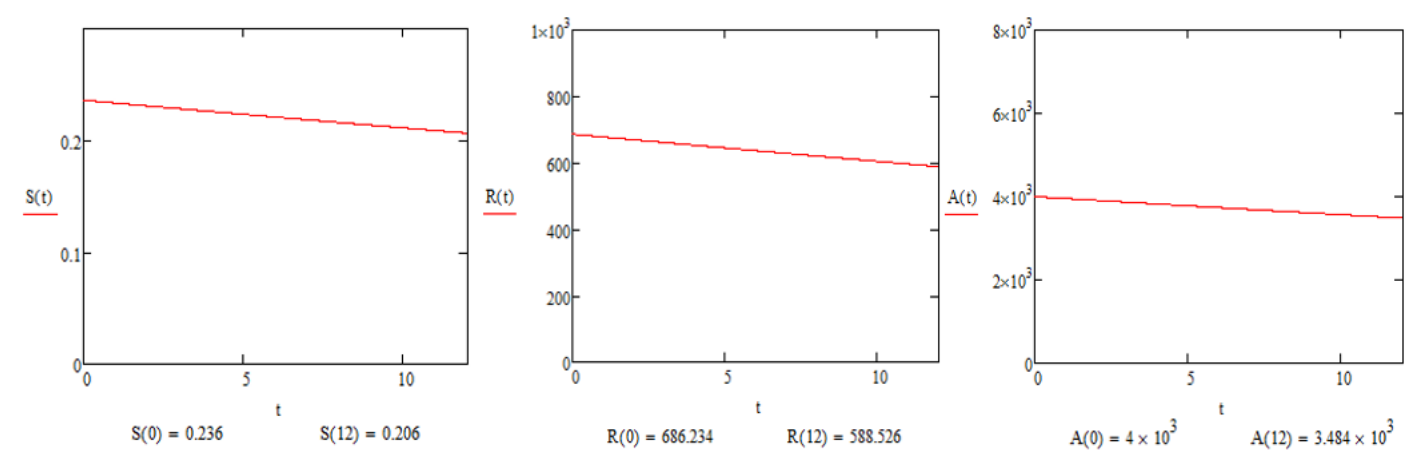

Рис. 3. Динаміка зліва-направо ринкової частки, прибутку та активів компанії (виражених у гр. од.)
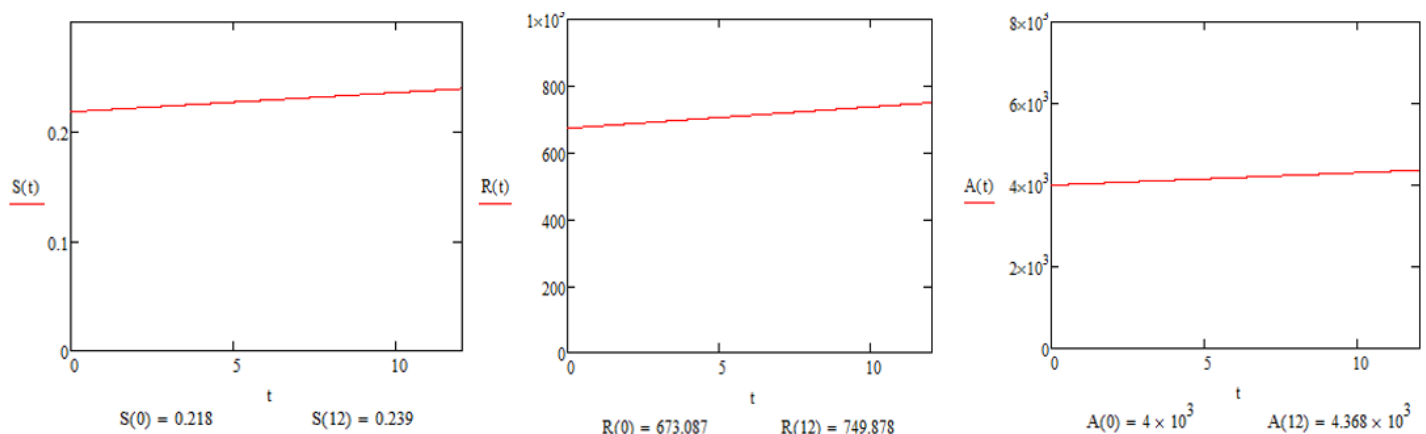

Рис. 4. Динаміка зліва-направо ринкової частки, прибутку та активів компанії (виражених у гр. од.)

Відмітимо, що, на відміну від отриманих результатів при реалізації 1-ї та 2-ї стратегій, при виведенні нового інноваційного продукту на ринок спостерігається позитивна динаміка розвитку всіх показників.

Результати порівняння трьох стратегій представлені у таблиці.

Таблиия

Порівняльна таблиця частки ринку, прибутку та активів компанії при різних стратегіях

\begin{tabular}{|c|c|c|c|}
\hline & Стратегія 1 & Стратегія 2 & Стратегія 3 \\
\hline $\mathrm{S}(0)$ & $21,8 \%$ & $23,6 \%$ & $21,8 \%$ \\
\hline $\mathrm{S}(12)$ & $19,2 \%$ & $20,6 \%$ & $23,9 \%$ \\
\hline $\mathrm{R}(0)$ & 673 & 686 & 673 \\
\hline $\mathrm{R}(12)$ & 577 & 588 & 720 \\
\hline$\sum_{t=1}^{12} R(t)$ & 7452 & 7606 & 7895 \\
\hline $\mathrm{A}(0)$ & 4000 & 4000 & 4000 \\
\hline $\mathrm{A}(12)$ & 3541 & 3484 & 4368 \\
\hline
\end{tabular}

Отже, при виборі компанією незмінної ціни товару (перша стратегія) спостерігається негативна динаміка всіх показників, при виборі стратегії збільшенні частки ринку за рахунок здешевлення товару (друга стратегія) - миттєве зростання частки ринку на початку, однак далі негативна динаміка, при введенні нового товару (третя стратегія) - позитивна динаміка показників. 
Таким чином, для збільшення частки ринку i, як наслідок, прибутку у перспективі 12 місяців, компанії рекомендується вивести на ринок новий продукт за рахунок інвестицій від материнської компанії.

Висновки. На основі побудованої моделі оцінки ринкової діяльності компанії з врахуванням частки ринку проаналізовано можливі стратегії поведінки компанії та запропонована ефективна стратегія. Результати аналізу показують, що частка ринку і прибуток будуть знижуватися, якщо компанія не буде вживати ніяких заходів. Стратегія здешевлення товару також дає в результаті негативну динаміку показників частки ринку, чистого прибутку та активів. Для подальшого позитивного розвитку компанії пропонується обрати стратегію виведення нового інноваційного продукту на ринок.

Запропонована модель дозволяє визначити напрям маркетингової стратегії компанії, оперуючи основними показниками ії діяльності, як фінансовими, так і маркетинговими: ринковою часткою, прибутком та розміром активів компанії.

\section{Лiтература:}

1. Егорова Н. Е. Динамические модели развития малых предприятий, использующих кредитно-инвестиционные ресурсы / Н. Е. Егорова, С. Р. Хачатрян. - Москва: ЦЭМИ PAH, 2001. $-44 \mathrm{c}$.

2. Егорова Н. Е. Применение дифференциальных уравнений для анализа динамики развития малых предприятий, использующих кредитно-инвестиционный ресурс / Н. Е. Егорова, С. Р. Хачатрян. // Экономика и математические методы. - 2006. - №1. - С. $50-67$.

3. Шерстенников Ю. В. Модель влияния темпов внедрения инновационных решений на дина-мику развития малого предприятия / Ю. В. Шерстенников, Л. В. Ромащук. // Економіка: проблеми теорії та практики: Збірник наукових праць. - 2007. - Т.5 №222 - C. $468-480$.

4. Жуковська О. А. Прийняття управлінських рішень про стратегію підприємства в умовах інтервальної невизначеності / О. А. Жуковська // XXI International Conference "Problems of decision making under uncertainties", 13-17 травня 2013 р., Сходниця, Україна : тези доп. - С. 134.

5. Жуковська О. А. Моделі прийняття економічних рішень щодо оптимальної кредитної стратегії за умов неповної інформації / О. А. Жуковська, К. О. Одінцова. // Економічний вісник. - 2013. - №9. - С. 543-551.

6. Жуковська О. А. Математична модель аналізу та прогнозування розвитку малого підприємства / О. А. Жуковська, В. В. Ковальова. // Збірник праць Інституту математики НАН України. - 2008. - Т. 5 №5 - С. 111-123.

7. Жуковська О. А. Формальна модель прийняття кредитного рішення малим підприємством / О. А. Жуковська, В. В. Ковальова. // Економіка: проблеми теорії та практики.Збірник наукових праць. - 2010. - Т.2 №260. - С. 421-427.

8. Marasco A. Market share dynamics using Lotka-Volterra models / A. Marasco, A. Picucci, A. Romano. // Technological Forecasting \& Social Change. - 2016. - №105. - C. 49-62.

9. Aravindakshan A. Advances in mathematical models in marketing / Aravindakshan A. Maryland: Graduate School of the University of Maryland, 2007. - 112 p.

10. Cooper L.G. Market-Share Analysis / L.G. Cooper, M. Nakanishi. - Netherlands: Kluwer Academic Publishers, 2010. - $271 \mathrm{p}$.

11. Kotler P. Marketing Management: Analysis, Planning, and Control, Fifth Edition / Kotler P. - Englewood Cliffs, NJ: Prentice-Hall, Inc - 1984.

12. Жуковська О. А. Економіко-математичне моделювання ємності ринку та ринкової частки компанії / О. А. Жуковська, П. А. Нікітіна. // Економічний вісник. - 2016. - №13. - C. 546-550. 
13. Жуковська О. А. Формальная модель оценки ёмкости рынка в условиях интервальной неопределенности / О. А. Жуковська. // Управляющие системы и машины. - 2008. №5. - С. 88-92. 